D.O.I: 10.3895 /gi.v1i1.1818

\title{
ANÁLISE DOS IMPACTOS DE CHOQUES EM PREÇOS DE INSUMOS: UMA APLICAÇÃO AOS CUSTOS COM TRIPULAÇÃO DE COMPANHIAS AÉREAS
}

\section{ANALYSIS OF COST SHOCKS IMPACTS ON INPUT PRICES: AN APPLICATION TO AIRLINE CREW COSTS}

\author{
Cícero Rodrigues de Melo Filho ${ }^{1}$; Alessandro Vinícius Marques de Oliveira ${ }^{2}$ \\ ${ }^{1}$ Instituto Tecnológico de Aeronáutica - ITA - Brasil \\ ciceromelofilho@gmail.com \\ ${ }^{2}$ Instituto Tecnológico de Aeronáutica - ITA - Brasil - ITA - São Paulo - Brasil \\ alessandro.oliveira@pq.cnpq.br
}

\begin{abstract}
Resumo
Este trabalho examina os impactos de choques nos custos com tripulação na competição entre companhias aéreas com produto diferenciado e assimetrias com relação ao tamanho da operação. Esse assunto tem sido frequentemente discutido no contexto dos pleitos dos sindicatos de aeronautas e aeroviários por maiores salários e melhores condições de trabalho, tanto no Brasil quanto em outros países. Em especial, no transporte aéreo, estudos indicam que o poder de pressão dos sindicatos pode ser elevado em relação a outras indústrias, por conta das especificidades da organização industrial do setor. Diante disso, foram realizadas simulações numéricas utilizando parâmetros estimados econometricamente para cenários com diferentes hipóteses relativas às economias de densidade. Os resultados indicam que, em uma situação de aumento exógeno nos salários, uma pequena companhia aérea é sempre mais impactada do que uma grande companhia aérea. Em um regime de fortes economias de densidade, a empresa menor incorre em maiores perdas de lucratividade. Essa situação é amenizada na presença de economias de densidade fracas. Conclusões finais sugerem que a competição entre as companhias aéreas é enfraquecida pelo fato de empresas menores terem um baixo poder de barganha junto aos sindicatos.
\end{abstract}

Palavras-chave: transporte aéreo; competição; custos com tripulação; economias de densidade.

\section{Introdução}

Nos últimos tempos muito tem sido discutido a respeito dos pleitos dos sindicatos de aeronautas e aeroviários por maiores salários e melhores condições de trabalho, tanto no Brasil quanto em outros países. Em especial, no transporte aéreo, estudos em economia do trabalho (Hirsch, 2007, e Bemmelech et al 2011), indicam que o poder de pressão dos sindicatos pode ser elevado em relação a outras indústrias, por conta das especificidades da organização industrial do setor. Em primeiro lugar, a mão de obra altamente especializada de pilotos e mecânicos pode ser de difícil reposição no curto prazo. Além disso, ao contrário de outros bens duráveis, os serviços de transportes não são estocáveis ou diferidos temporalmente (Hirsch, 2007). Por fim, os consumidores 
podem buscar alternativas modais ou mesmo reduzir a frequência de viagens. Essas condições próprias à organização da indústria podem tornar a ameaça de greve um instrumento crível que pode incrementar consideravelmente o poder de barganha dos sindicatos. Em condições de expansão de demanda, a habilidade dos sindicatos de extrair ganhos salariais torna-se mais acentuada.

No caso brasileiro, essa situação foi exacerbada durante a aceleração do crescimento do setor de transporte aéreo nos últimos anos, cuja consequência mais nítida foi o rápido incremento de procura por mão-de-obra qualificada para o setor, insumo escasso, a uma velocidade acima daquela necessária para formar novos pilotos e comissários.

Uma particularidade do ambiente institucional brasileiro precisa ser anotada, pois dela resulta a assimetria de condições de concorrência entre empresas aéreas de porte grande e de porte grande, conforme será examinada neste artigo. Trata-se do desenho de relações de trabalho, que seguem o modelo legislado e não o modelo contratual. Significa dizer que grande parte dos custos de mão-de-obra que irão impactar as empresas estão definidos pela legislação, como a definição de pisos salariais com base em acordos entre sindicatos de empresas e empregados, assim como itens de custo importante, com extensão de jornada de trabalho, número de tripulantes por aeronave, horas-extras, dentre outros. Assim, os custos de mão-de-obra tornam-se tipicamente exógenos, não tendo as empresas, individualmente, flexibilidade para administrar seus custos.

$\mathrm{O}$ aumento da procura por tripulantes no transporte aéreo tem consequências importantes, como o aumento do poder de barganha dos sindicatos. Essa problemática pode ser ilustrada com as recentes ameaças de greve às vésperas do natal de 2010, em reivindicação por aumentos salariais e melhores condições de trabalho. Conforme Fernandes (2010), recentemente os aeroviários, que são os trabalhadores das companhias aéreas que operam em terra, reivindicaram junto às companhias aéreas um aumento de $13 \%$, enquanto os aeronautas, que são os comissários de bordo, pilotos e mecânicos de voo, reivindicaram um aumento de 15\%. Por outro lado, as empresas propuseram reajustes iguais ao Índice Nacional de Preços ao Consumidor (INPC), algo em torno de 6\%. Para evitar uma greve e prejudicar ainda mais os usuários do transporte aéreo, o Tribunal Superior do Trabalho concedeu uma liminar determinando que $80 \%$ dos funcionários do setor aéreo não entrassem em greve. O objetivo dessa ação judicial foi o de viabilizar o transporte aéreo em todo o território nacional, no período compreendido entre 23 de dezembro de 2010 e 2 de janeiro de 2011, sendo esse período considerado de alta temporada e grande volume de passageiros. Os sindicatos naquele momento decidiram em assembleia suspender temporariamente a greve em cumprimento à decisão judicial. Como desfecho dessa história, de acordo com Fonseca (2011), após quase dois meses de negociações, os sindicatos e as empresas aéreas chegaram a um acordo, onde os aeroviários e aeronautas conquistaram $10 \%$ de aumento nos pisos salariais e $8,75 \%$ de reajuste nos 
salários e demais itens econômicos. Essa situação serve para ilustrar como os sindicatos brasileiros fortaleceram-se ao longo do tempo em comparação a períodos anteriores, o que de certa forma beneficia os funcionários e pressionam as empresas cada vez mais por melhores salários e condições de trabalho. Em países como Alemanha, Reino Unido, Áustria e Estados Unidos, os sindicatos possuem importância significativa na formulação de diretrizes e na execução de política econômica.

O poder de pressão sindical tem relação direta com possíveis elevações nos custos com tripulação, dado que os pisos salariais são sempre definidos em reuniões entre os Sindicatos dos Aeronautas (SNA) e os Sindicatos das Empresas Aéreas (SNEA). Esses tetos de preços definidos valerão para todas as empresas independentemente de seus respectivos tamanhos e independente dos funcionários serem ou não filiados a sindicatos, característica das relações de trabalho regidas mais por legislação do que por contrato, como é o caso do Brasil.

Esse trabalho fará algumas previsões sobre a possibilidade de choques em custos, sendo que esses choques serão situações onde os custos com tripulação serão elevados de forma exógena, ou seja, algum fator externo fará com os custos se alterem. Dessa forma, com uma alteração dos custos as empresas sofrerão impactos negativos, de forma a ter de elevar os preços, consequentemente perder passageiros e lucros.

Choques exógenos em custos refletem os fatores externos às empresas que podem fazer com que os custos se elevem. Esses fatores são compostos por uma infinidade de possibilidades, dentre elas, um aumento no poder dos sindicatos (que passaria a pressionar as empresas por maiores salários), uma escassez de mão-de-obra (o que faria com que as empresa tivessem que elevar os salários das tripulações para mantê-las), uma modificação na legislação de forma a permitir que as tripulações trabalhem menos (fazendo com que as empresas sejam obrigadas a contratar mais tripulantes), dentre outras possibilidades. Esse trabalho faz suas simulações baseadas em uma situação de aumento de poder dos sindicatos, mas toda a análise quantitativa valerá para qualquer choque exógeno nos custos com tripulação.

O objetivo desse trabalho foi desenvolver, através de uma modelagem da Teoria da Organização Industrial, um estudo dos efeitos de choques exógenos no valor do insumo trabalho, nos preços das passagens aéreas, na quantidade de passageiros, na receita total, no custo total e na competitividade de companhias aéreas, sob a hipótese de economia de densidade. A contribuição desse estudo está na análise de efeitos combinados de choques em custos com tripulação com economia de densidade. Na literatura consagrada existente, já existem modelos de competição com diferenciação de produto, porém o diferencial deste trabalho está na inserção da economia de densidade combinada com variações exógenas de custos das empresas aéreas, de forma a capturar 
os efeitos na competição de forma mais realista, embora a modelagem utilizada nesse trabalho seja linear.

Esse trabalho será organizado da seguinte forma. A Seção 2 apresenta uma breve análise dos custos com tripulação das companhias aéreas. A Seção 3 contém a revisão de literatura relativa ao tema e apresenta uma modelagem de competição entre empresas aéreas na presença de economias de densidade e de choques em custos. A Seção 4 apresenta os resultados da modelagem, sendo seguido pelas Conclusões.

\section{Custos com tripulação}

Segundo Doganis (2001), com a desregulação econômica do transporte aéreo, e em especial a partir dos anos 1990, tem-se dado maior atenção aos custos com mão-de-obra, tendo em vista que esse é um dos maiores fatores de diferenciação de uma empresa para outra. Nos Estados Unidos, esses custos representam uma proporção entre 25 e $40 \%$ dos custos totais. Na Europa eles representam entre 20 e $35 \%$ dos custos totais. Na Ásia eles representam entre 15 e $20 \%$ dos custos totais.

No Brasil, os custos com tripulação representam a segunda maior parcela dos custos de uma empresa aérea. Os impactos desses custos em uma empresa aérea dependem de vários fatores, dentre eles dos acordos sindicais para a definição de salários e reajustes. A partir dessa hipótese (pressão dos sindicatos) é desenvolvido o modelo que será estudado nesse trabalho. A Figura 1, mostra a variação dos custos com tripulação por passageiro, em empresas selecionadas, no período de 2000 a 2010.

Figura 1 - Exemplo de figura

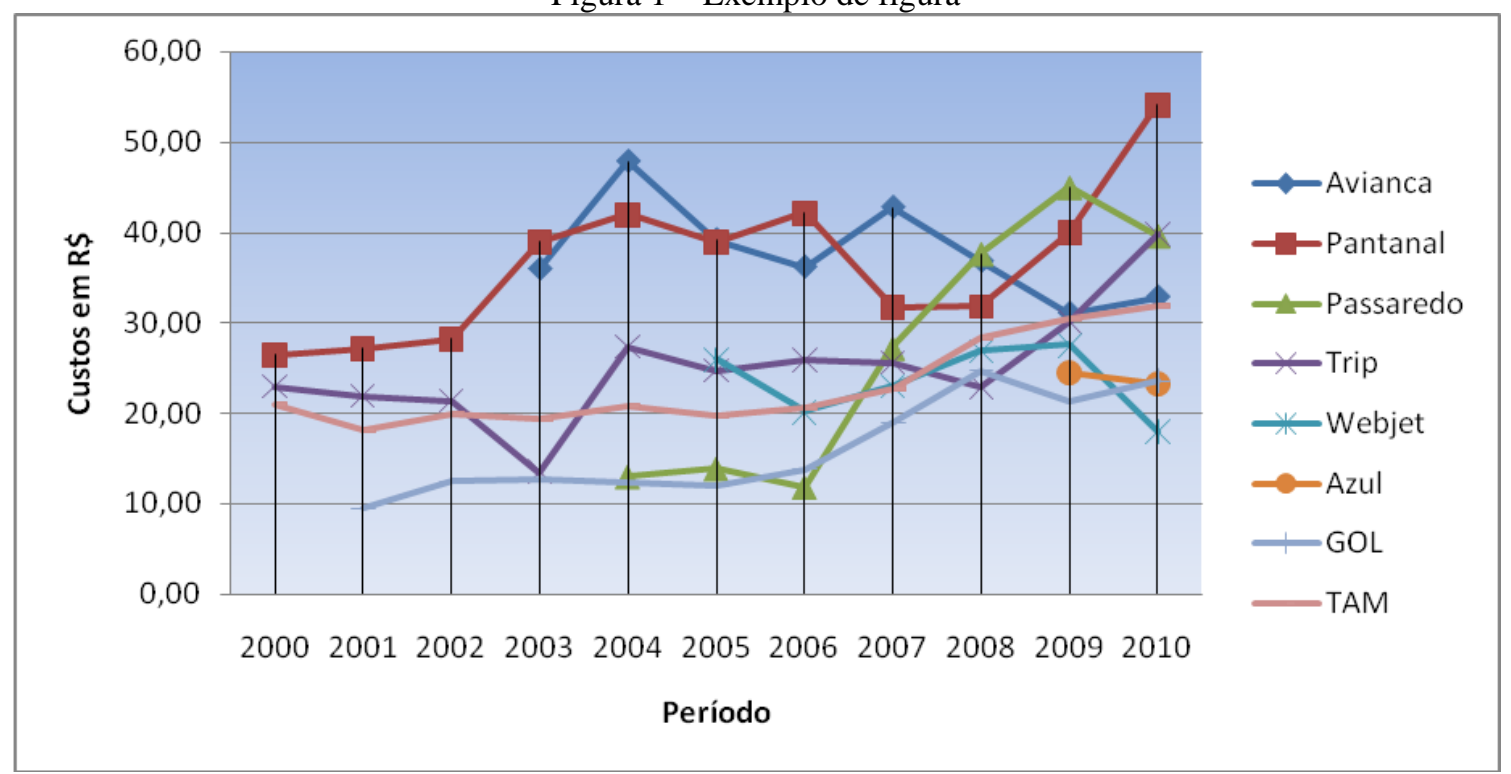

Fonte: Anuário Econômico ANAC (diversos anos) 
A análise da Figura 1, permite inferir que, em geral, as empresas maiores têm um custo com tripulação por passageiro menor que empresas menores. Essa situação pode ser explicada pelo fato das empresas menores possuírem, em geral, aeronaves menores e pela legislação prever uma tripulação mínima por aeronave, o que aumenta os custos com tripulação. As empresas maiores, por utilizarem aeronaves maiores, aproveitam-se da economia de densidade, conseguindo diluir melhor os custos com tripulação entre os passageiros. O presente trabalho fará análises adiante a respeito dos benefícios da economia de densidade na competitividade de empresas maiores com empresas menores, assim como uma análise mais aprofundada do conceito de economia de densidade.

A Figura 2 mostra a relação do custo médio por passageiro com tripulação, pelo load factor e pela etapa média, onde o tamanho das "bolas" são o tamanho das etapas, o eixo y é o custo médio por passageiro com tripulação, e o eixo x é o load factor. As empresas com cor amarela são aquelas consideradas pequenas, as com cor verde são as consideradas intermediárias e as empresas em cor azul são as consideradas grandes. Os dados para elaboração dessa figura foram retirados dos anuários econômicos da ANAC.

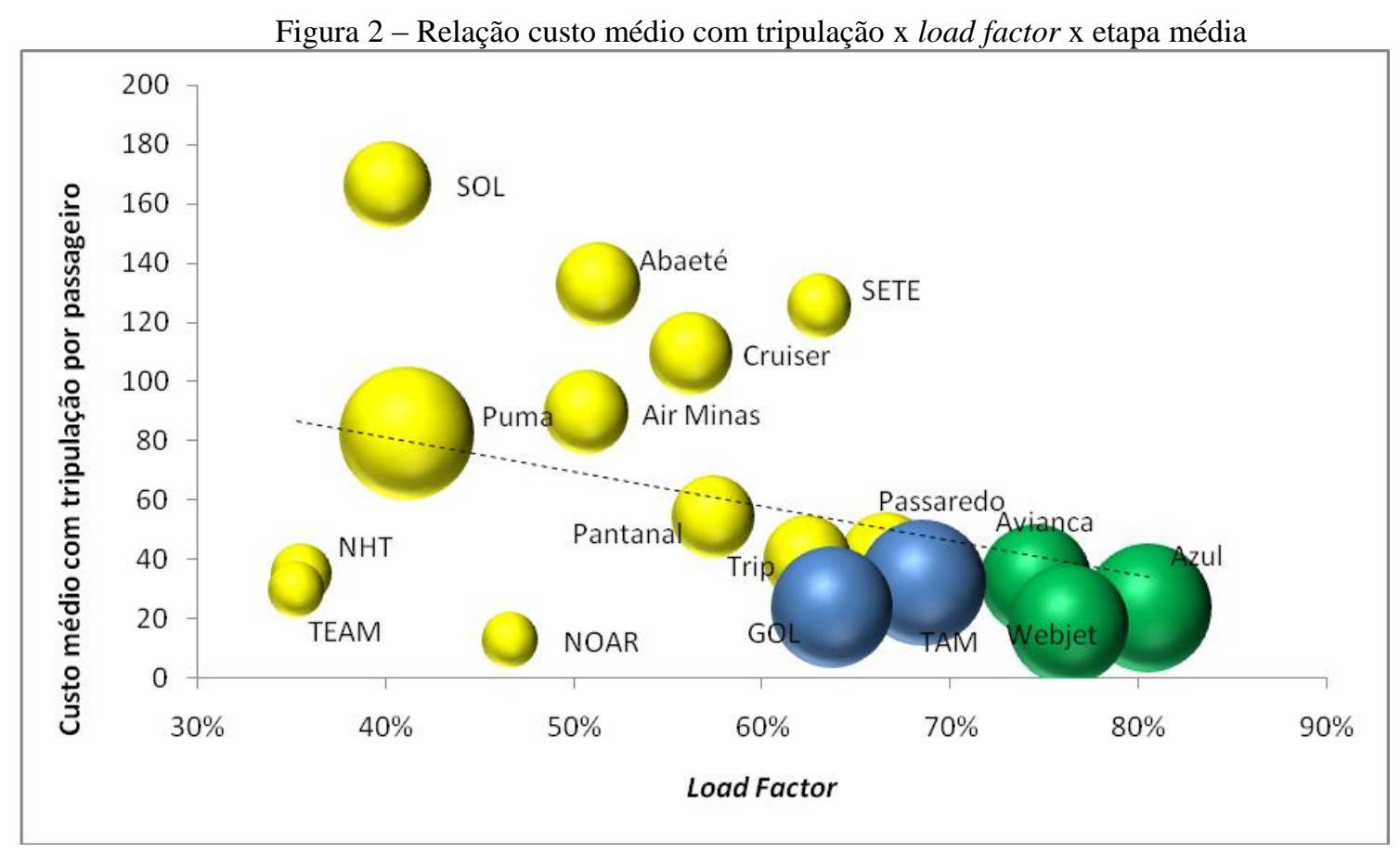

Fonte: Anuário Econômico ANAC - diversos anos

A análise dessa figura permite concluir que empresas com uma maior densidade, possuem custos menores, ou mais diluídos, do que as empresas que possuem menor densidade, além disso pode-se perceber que em geral as empresas com etapas maiores são as empresas maiores e que consequentemente conseguem voar com um grau de lotação maior, já as empresas menores são em geral as com etapas menores e com um grau de lotação menor. Dessa forma, pode dizer que as empresas menores em geral não se beneficiam dos ganhos com densidade na rota. 


\subsection{Por que os custos com tripulação?}

Para análise desse trabalho foram escolhidos os custos com tripulação pelo fato de serem custos significativos para as empresas aéreas, além de serem uma parte dos custos que dependem de fatores estritamente exógenos, como os acordos com os sindicatos. Além disso, os custos com tripulação dependem de certa forma da legislação vigente, não para os valores dos salários (que em geral são definidos tetos mínimos em acordos com os sindicatos), mas pela quantidade de tripulantes que deve ter cada tipo de aeronave, além da quantidade de horas que cada tripulante pode ter de voo, entre outras questões definidas em lei, que no entanto afetam as empresas de forma significativa, tendo em vista que a quantidade de horas que a tripulação pode ter afetará significativamente nos custos, sendo que se as tripulações puderem voar mais tempo, cairão os custos com tripulação por passageiro, o que reduzirá os custos das empresas.

Alguns países da América do Sul já possuem legislações mais flexíveis que a do Brasil, com é o caso de Chile, Peru, Uruguai, dentre outros. Assim, as empresas desses países acabam obtendo vantagens em relação às empresas brasileiras. É importante ressaltar que o presente trabalho não tem como objetivo fazer proposições de mudanças na legislação, mas sim indicar o que de certa forma está ultrapassado em comparação a outros países, e que, caso fosse alterado, reduziria custos das empresas aéreas, além de mostrar que os custos com tripulação impactam de forma diferente empresas grandes e empresas menores, em situações de choques em custos. As possibilidades de mudanças na legislação serão apenas supostas como forma de avaliar possíveis reduções nos custos das empresas aéreas.

\section{Modelagem da Competição entre Empresas Aéreas na Presença de Economias de Densidade e de Choques em Preços de Insumos}

A literatura específica que aborda os impactos causados por possíveis elevações dos custos com tripulação na competição entre empresas aéreas com produto diferenciado é bastante limitada. Para esse trabalho foi desenvolvido um modelo semelhante ao proposto por Dixit (1979), e utilizado por Singh e Vives (1984) e Fu, Lijesen e Oum (2006), sendo que este último fez uma aplicação ao transporte aéreo, porém com custos com tarifas aeroportuárias. Dentre outros trabalhos que utilizaram demanda linear, pode-se citar Brueckner e Picard (2011), que também trabalharam com economia de densidade linear, suposição parecida com a proposta nesse trabalho, porém com aplicação diferente.

O presente trabalho apresenta uma extensão ao trabalho de Fu, Lijesen e Oum (2006), que já utiliza uma modelagem clássica e consagrada na literatura econômica, já aplicada ao transporte aéreo, porém fazendo uma análise para os custos com tarifas aeroportuárias. Já o presente trabalho 
fará as adaptações para aplicações aos custos com tripulação. Além disso, serão inseridos os ganhos com densidade que as empresas menores têm em relação às grandes, o que de certa forma reduz os impactos de uma possível elevação de custos na competição entre uma empresa grande e uma empresa menor.

Fu, Lijesen e Oum (2006), faz um estudo acerca dos impactos de uma elevação das tarifas aeroportuárias e seu respectivo impacto na competição entre uma empresa full service airlines (FSA) e uma low cost carriers (LCCs). Segundo esse estudo os aeroportos são fornecedores de insumos essenciais para as companhias aéreas, portanto pode-se dizer que quando as tarifas aeroportuárias são elevadas acima de um determinado nível visto como socialmente ótimo, o volume de viagens aéreas será reduzido para um nível abaixo do que é determinado como socialmente ótimo o que levará a uma perda do bem-estar social. Essa questão vem sendo estudada na literatura da dupla marginalização e da regulação de monopólio natural, porém até o momento o impacto das taxas aeroportuárias na concorrência entre as companhias aéreas tem recebido pouca atenção. Atenção muito menor tem sido dada aos impactos da alteração das tarifas aéreas sobre a concorrência entre uma full service airlines (FSA) e uma low cost carriers (LCCs). De acordo com esse estudo essa problemática merece uma análise, tendo em vista que empresas LCC e empresas de menor porte aparentemente são mais sensíveis à elevação de custos, como custos com encargos aeroportuários, custos com mão-de-obra, dentre outros.

\subsection{Modelagem Teórica}

A O modelo proposto nesse trabalho tem como característica ser um duopólio, com produto heterogêneo, que significa qualidade percebida pelo usuário distinta, a competição é em preços “jogo de Bertrand-Nash”, e as empresas não cooperam entre si, ou seja, o jogo é não cooperativo. Ao longo desta seção, assume-se a empresa 1 como sendo uma empresa maior, e 2 como sendo uma empresa menor, ambas voltada para um sistema de demanda apresentado em (1)

$$
\left\{\begin{array}{l}
q_{1}=\alpha_{1}-\beta_{1} p_{1}+\gamma_{1} p_{2} \\
q_{2}=\alpha_{2}-\beta_{2} p_{2}+\gamma_{2} p_{1}
\end{array}\right.
$$

A Função lucro total da firma 1 ( $\left.\pi_{1}\right)$ e a da firma $2\left(\pi_{2}\right)$, é dada por (2):

$$
\left\{\begin{array}{l}
\pi_{1}=R T_{1}-C T_{1}=p_{1} q_{1}-C T_{1}\left(q_{1}\right) \\
\pi_{2}=R T_{2}-C T_{2}=p_{2} q_{2}-C T_{2}\left(q_{2}\right)
\end{array}\right.
$$

A função custo total, das empresas 1 e 2, é apresentada abaixo em (3): 


$$
\left\{\begin{array}{l}
C T_{1}=C F_{1}+c_{1} q_{1}-\varphi q_{1}^{2} \\
C T_{2}=C F_{2}+c_{2} q_{2}-\varphi q_{2}^{2}
\end{array}\right.
$$

O custo marginal é dado em (4) por:

$$
\left\{\begin{array}{l}
C m g_{1}=\frac{\partial C T_{1}\left(q_{1}\right)}{\partial q_{1}}=c_{1}-2 \varphi q_{1} \\
C m g_{2}=\frac{\partial C T_{2}\left(q_{2}\right)}{\partial q_{2}}=c_{2}-2 \varphi q_{2}
\end{array}\right.
$$

A condição de primeira-ordem para maximização de lucros da firma 1 e da firma 2 é dada em (5):

$$
\left\{\begin{array}{l}
\pi_{1}{ }^{\prime}=\frac{\partial \pi_{1}\left[p_{1}, q_{1}\left(p_{1}\right)\right]}{\partial p_{1}}=q_{1}+p_{1} \frac{\partial q_{1}}{\partial p_{1}}+c_{1} \frac{\partial q_{1}}{\partial p_{1}}+\varphi \frac{\partial q_{1}^{2}}{\partial p_{1}}=0 \\
\pi_{2}{ }^{\prime}=\frac{\partial \pi_{2}\left[p_{2}, q_{2}\left(p_{2}\right)\right]}{\partial p_{2}}=q_{2}+p_{2} \frac{\partial q_{2}}{\partial p_{2}}+c_{2} \frac{\partial q_{2}}{\partial p_{2}}+\varphi \frac{\partial q_{2}^{2}}{\partial p_{2}}=0
\end{array}\right.
$$

A solução da Equação (5) é muito extensa. Diante disso, a solução será obtida computacionalmente através do Método quasi-newton. Esse método busca as soluções de otimização, dadas as restrições do modelo, com isso ele encontra os valores ótimos.

A solução da equação (5) fornecerá o valor para o qual os preços migrarão em caso de elevação dos custos da empresa 1 e da empresa 2, com um efeito combinado com economia de densidade. Essa elevação dos custos pode ser de qualquer natureza variável como, por exemplo, fruto de incremento nos custos com tripulação. A partir dos preços de equilíbrio ( $p_{1}$ e $p_{2}$ ), é formado o equilíbrio de Nash, já que neste ponto cada firma está adotando a melhor estratégia (preço) possível dado a estratégia (preço) adotada pela sua rival, nesse ponto nenhuma firma possui incentivos para desviar desse resultado final.

\subsection{Aplicação ao Mercado Brasileiro}

A base de dados utilizada para a estimação da modelagem empírica de demanda e custos desse trabalho foi fornecida pela Agência Nacional de Aviação Civil (ANAC), através de seus anuários estatísticos. Os dados são compostos por um conjunto de informações publicadas e nãopublicadas, e estão dispostos na forma de painel com efeitos fixos, para o período amostral de janeiro de 1997 a setembro de 2001, para as companhias aéreas Varig (VR), Rio-Sul (RS), TAM (TA), Vasp (VP) e Transbrasil (TB). A periodicidade dos dados é mensal. O mercado é considerado 
na forma direcional, de forma que os dados compreendem informação tanto do par de aeroportos Congonhas - Santos Dumont (CGH-SDU), quanto Santos Dumont - Congonhas (SDU-CGH).

Esse trabalho utiliza o modelo de Painel de Dados, onde a estrutura dos dados coletados está na forma de cross-section de ligações aéreas e companhias aéreas (duas dimensões), ao longo do tempo (terceira dimensão). A forma mais recente, encontrada em literatura, para o tratamento econométrico desse tipo de estrutura de dados é via modelo de regressão com estimador de efeitos fixos (típicos de Painel de Dados).

Christensen (2002) define efeitos fixos como sendo um modelo estatístico que representa as quantidades observadas em termos de variáveis explicativas. Essas variáveis explicativas são tratadas como se não fossem aleatórias, ou seja, está em contraste com os modelos de efeitos aleatórios e modelos mistos em que todas ou algumas das variáveis explicativas são tratadas como se resultarem de causas aleatórias. Muitas vezes, a mesma estrutura do modelo, que normalmente é um modelo de regressão linear, pode ser tratado como qualquer um dos três tipos, dependendo da ótica do analista, embora possa haver uma escolha natural em qualquer situação.

$\mathrm{Na}$ análise de dados em painel, o termo estimador de efeitos fixos é usado para se referir a um estimador de coeficientes no modelo de regressão. Se for assumido efeitos fixos, será imposto um tempo independente para cada entidade que possivelmente esteja correlacionada com os regressores. Além disso, de acordo com Vassallo (2010), "a inserção de controladores de efeitos fixos no modelo proporciona uma maior qualidade na estimação dos efeitos das demais variáveis no processo de decisão do consumidor, sem recurso ao uso de proxies arbitrárias para o tamanho do mercado, como é tipicamente encontrado na literatura."

A partir de então, será apresentada a equação de demanda empírica (6) equivalente à equação de demanda algébrica apresentada em (1), e a equação de custos empírica (7) equivalente à equação de custos apresentada em (3).

$$
\begin{aligned}
& q j=f\left(p j_{-} r g t a s l, p_{-} j_{-} \text {rgtasl, gdp_rgtasl, } p j_{-} v p t b, p_{-} j_{-} v p t b, g d p_{-} v p t b,\right. \\
& \text { jyper }, \text { dfire, jpaer, jvptb, jtatb, jrgsl,quars })
\end{aligned}
$$

A variável dependente $q j$ representa a média diária de passageiros pagantes transportados pela companhia aérea $j$ em uma dada direção do mercado constituído pelo par de aeroportos Congonhas - Santos Dumont. A média é computada dividindo-se o total de passageiros pagantes transportados em um determinado mês pela companhia aérea, pelo número de dias do mês. qj é, portanto, uma variável de tráfego (nos modelos de demanda) e uma variável de produto (nos modelos de custos e oferta) da companhia aérea. No cômputo do $q j$ são considerados apenas os passageiros locais, ou seja, aqueles com origem e destino efetivo nos aeroportos considerados, 
sendo excluídos os passageiros em trânsito ou conexão.

A variável pj mede o preço médio mensal da companhia aérea $j$, sendo computado a partir da divisão da receita total da companhia aérea em um determinado mês na ligação, pelo número de passageiros transportados pagantes. Já a variável $p_{-} j$ mede o preço médio mensal das companhias aéreas rivais da companhia $j$. O preço médio das companhias rivais é computado ponderando-se o preço médio de cada companhia pelo número de passageiros pagantes da mesma. As variáveis de preço médio são deflacionadas pelo Índice Nacional de Preços ao Consumidor Amplo (IPCA) do Instituto Brasileiro de Geografia e Estatística (IBGE).

A variável pj_rgtasl é construída multiplicando-se pj por rgtasl, esta última sendo uma variável binária (dummy) indicativa das empresas Varig, Tam e Rio-Sul. Já pj_vptb é construída multiplicando-se pj por $v p t b$, esta última sendo uma variável binária (dummy) indicativa das empresas Vasp e Transbrasil. Com relação a $p_{-} j_{-}$rgtasl e $p_{-} j_{-} v p t b$, essas são também variáveis obtidas da interação entre as respectivas dummies e a variável $p_{-} j$.

A variável $g d p$ mede o Produto Interno Bruto (PIB) do país, em seu cômputo mensal obtido a partir de série histórica do Banco Central do Brasil. A série é deflacionada utilizando-se o IPCA do IBGE. A variável $g d p \_r g t a s l$ é o resultado da multiplicação entre a variável $g d p$ e a dummy rgtasl. A variável $g d p_{-} v p t b$ é o resultado da multiplicação entre a variável $g d p$ e a dummy $v p t b$.

jyper é uma variável dummy que controla os efeitos fixos interagidos de companhia aérea (j), ano (y) e período do ano (per). Essa variável é obtida multiplicando-se cada uma dessas dummies (interação). Os períodos do ano para cômputo da variável per são dois: férias (janeiro, fevereiro e julho) e fora das férias (resto do ano);

dfire é uma variável dummy que controla os efeitos do incêndio que ocorreu no aeroporto Santos Dumont no Rio de janeiro em meados de 1998, onde o aeroporto ficou fechado por um determinado período para reformas. Essa variável faz o controle desse período de inatividade do aeroporto nos dados, sendo computada para o período entre fevereiro e julho de 1998.

jpaer controla o efeito do acordo de compartilhamento de aeronaves das empresas aéreas na ponte aérea. jvptb controla os efeitos do compartilhamento que ocorreu entre as empresas Vasp e Transbrasil. Já a variável jtatb controla os efeitos do compartilhamento de aeronaves entre as empresas TAM e Transbrasil por um determinado período. A variável jrgsl controla os efeitos nos dados do compartilhamento de aeronaves entre as empresas Varig e Rio Sul. Vale ressaltar que a Rio Sul pertencia à Varig. 
Por fim, quars controla os trimestres para as empresas, ou seja, ano 1 trimestre 1, 2 e 3, ano 2 trimestre 4, 5 e 6 , e assim sucessivamente.

$$
t c j=f\left(q j_{-} \text {rgtasl }, q j_{-} v p t b, q j 2, d f i r e, q u a r s\right)
$$

A variável dependente ${ }^{t c j}$ representa o custo total da empresa j, obtido através da soma de todos os itens de custos operacionais e não operacionais da empresa. Por definição, o custo total é o somatório do custo fixo com a parte variável dos custos. Essa parte variável depende da demanda. As variáveis de custos são deflacionadas pelo IPCA do IBGE.

A variável $q j \_r g t a s l$ é construída multiplicando-se $q j$ por rgtasl, esta última sendo uma variável binária (dummy) indicativa das empresas Varig, Tam e Rio-Sul. E qj_vptb é construída multiplicando-se $q j$ por $v p t b$, esta última sendo uma variável binária (dummy) indicativa das empresas Vasp e Transbrasil.

Ambas as regressões, a de demanda e a de custos, garantem que o processamento foi realizado com correção robusta de White, garantindo controle dos problemas de heteroscedasticidade e autocorrelação, que é uma medida que informa o quanto o valor de realização de uma variável é capaz de influenciar as outras variáveis, por exemplo, o quanto a existência do valor de um determinado parâmetro condiciona valores aos outros parâmetros.

\subsection{Resultados das estimações}

\subsubsection{Lado da demanda}

O intercepto que acompanha a variável pj_rgtasl, é dado por $\beta_{1}$. Ele mede o impacto no preço nas empresas Varig, TAM e Rio Sul, que são as com qualidade percebida melhor, já $\beta_{2}$ é o intercepto que acompanha $p j_{-} v p t b$, que mede o impacto no preço das empresas Vasp e Transbrasil, que são as com qualidade percebida pior. O intercepto $\gamma_{1}$ acompanha a variável $p_{-} j_{-}$rgtasl, que mensura o impacto do preço da rival, no caso as empresas com qualidade pior, na demanda das empresas com qualidade percebida melhor, e o intercepto $\gamma_{2}$ acompanha a variável $p_{-} j_{-} v p t b$, que mensura o impacto do preço da rival, no caso as empresas com qualidade melhor, na demanda das empresas com qualidade percebida pior. Os resultados das estimações são apresentados na Figura 3. 
Figura 1 - Parâmetros de demanda estimados econometricamente ${ }^{1}$

\begin{tabular}{lc}
\hline & $\begin{array}{c}(1) \\
q j\end{array}$ \\
\hline pj_rgtas1 & $-4.2659 * * *$ \\
p_j_rgtas1 & {$[1.088]$} \\
& $3.3685 * * *$ \\
gdp_rgtas1 & {$[1.040]$} \\
$9.3875 * *$ \\
pj_vptb & {$[4.664]$} \\
p_j_vptb & {$[0.9484 * * *$} \\
gdp_vptb & $4.9055^{* * *}$ \\
& {$[1.105]$} \\
& 0.3553 \\
& {$[4.476]$} \\
\hline N & 572 \\
adj. R-sq & 0.934 \\
\hline
\end{tabular}

A análise da Figura 3 permite inferir que para determinado aumento de preços, a empresa 1 (aquela com qualidade percebida melhor) perde 4,27 passageiros, e ganha da rival 3,37 passageiros. Já a empresa 2 (aquela com qualidade percebida pior) perde 8,95 passageiros e ganha da rival 4,91 passageiros. Dessa forma, pode-se observar que apenas pela análise dos parâmetros, que a empresa com qualidade percebida pior, sofre perdas relativamente maiores que a rival com qualidade melhor. Pela análise da Figura 3, percebe-se que a empresa 1 absorve menos passageiros da rival do que a empresa 2, porém ao se analisar o saldo global de perda (subtraindo a demanda que se perdeu pela demanda que se ganhou), é visível que a empresa 2 perde mais, pois enquanto a empresa com qualidade percebida melhor tem uma perda global de 0,9, a empresa com qualidade percebida pior tem uma perda global de 4,04 passageiros.

Por outro lado uma análise do produto interno bruto permite inferir que com o crescimento do país a empresa maior consegue obter maiores ganhos de demanda que a empresa menor, que é aquela com qualidade pior, o que de certa forma pode ser explicado pelo fato de que com o crescimento do país e da renda, a população passa a escolher serviços de melhor qualidade, nesse caso específico pode ser horários mais flexíveis, melhor serviço de solo, de bordo, aeronaves mais confortáveis, dentre outros.

A variável $p j \_r g t a s l$, que mede o impacto do preço da empresa menor na empresa grande de melhor qualidade, é correlacionada negativamente com a demanda qj, o que já era esperado, pelo fato de que quanto maior o preço mais propenso a perder demanda está a empresa, porém essa perda é significativamente menor que a da empresa menor, dado que a variável $p j_{-} v p t b$, que mede o impacto do preço da empresa grande na empresa menor, é correlacionada negativamente com a demanda, porém o coeficiente é quase o dobro do coeficiente da empresa grande, o que mostra que as perdas de demanda com uma elevação dos preços é maior na empresa menor e de qualidade

\footnotetext{
${ }^{1}$ Erros padrões estimados em colchetes e representações de $\mathrm{p}$-valor:***p<0,01, ${ }^{* *} \mathrm{p}<0,05,{ }^{*} \mathrm{p}<0,10$.
} 
inferior.

A variável $p_{-} j_{-}$rgtasl, que mede o impacto de um aumento de preços da empresa menor e com qualidade inferior na empresa maior, é correlacionada positivamente com a demanda, o que também já era de certa forma esperado, dado que quanto maior o preço cobrado pela empresa rival maior vai ser a absorção de demanda pela outra empresa, ou seja, se a empresa maior aumenta seus preços, a empresa menor absorve parte dos passageiros que deixaram de voar com a empresa que elevou os preços, o mesmo vale para a variável $p_{-} j_{-} v p t b$, que mede o impacto de um aumento de preços da empresa maior na empresa menor, ou seja, caso a empresa maior aumente seus preços parte dos passageiros que não estão dispostos a pagar pelo aumento, ou que atingiram o nível máximo que estariam dispostos a pagar por aquele serviço, migram para a empresa menor e com qualidade pior.

A variável $g d p_{-}$rgtasl, que mede o impacto do crescimento do PIB na empresa maior, é correlacionada com a demanda, ou seja, quanto maior o crescimento do PIB maior será a quantidade de pessoas que irão optar por usar o transporte aéreo. Já a variável $g d p \_v p t b$, que mede o impacto do crescimento do PIB na demanda da empresa menor, embora também seja correlacionada positivamente com a demanda, não apresenta coeficiente estatisticamente significante.

\subsubsection{Lado dos custos}

O intercepto de custos que acompanha a variável $q j$ _ rgtasl é dado por $c_{1}$. Ele mede o impacto da demanda nos custos das empresas Varig, TAM e Rio Sul, que são as com qualidade percebida melhor, já $c_{2}$ é o intercepto de custos que acompanha $p j \_v p t b$, que mede o impacto da demanda no preço das empresas Vasp e Transbrasil, que são as com qualidade percebida pior. Por fim, o parâmetro $\varphi$ é a economia de densidade, ou seja, ele mede o valor da economia de densidade presente. Os resultados dessa estimação são apresentados na Figura 4.

Figura 2 - Parâmetros de custo estimados econometricamente ${ }^{2}$

\begin{tabular}{|c|c|}
\hline & $\begin{array}{l}\text { (1) } \\
\text { tcj }\end{array}$ \\
\hline qj_rgtas1 & $113.6686^{* * *}$ \\
\hline qj_vptb & $108.7129 * * *$ \\
\hline$q j 2$ & $\begin{array}{l}-0.0216 * * * \\
{[0.006]}\end{array}$ \\
\hline $\begin{array}{l}\mathrm{N} \\
\text { adj. R-sq }\end{array}$ & $\begin{array}{r}572 \\
0.802\end{array}$ \\
\hline
\end{tabular}

\footnotetext{
${ }^{2}$ Erros padrões estimados em colchetes e representações de p-valor: $* * * p<0,01, * * p<0,05, * \mathrm{p}<0,10$.
} 
A análise da Figura 4 permite inferir que o intercepto de custo da empresa 1, que é aquela com qualidade percebida pelo usuário como melhor, é de 113,67, que representa um intercepto de custo de $4,4 \%$ a mais do que o rival que possui uma qualidade percebida inferior, e possui um intercepto de custo de 108,72. O fato do intercepto de custo da empresa 1 (aquela com qualidade melhor) ser maior que o da empresa 2 (aquela com qualidade inferior), está relacionado com os gastos que a empresa tem para garantir o máximo possível de conforto para seus usuários, seja no serviço de bordo nas aeronaves, seja nas salas de embarque no aeroporto. Essa figura apresenta também a Economia de Densidade dada por $\varphi$, esse parâmetro mede o grau de agressividade do mercado, ou seja, quanto maior for o parâmetro de conduta, menor é a competição no mercado, e quanto menor for o $\varphi$, maior é o grau de competição no mercado.

Os parâmetros $c_{1}$ e $c_{2}$, estimados econometricamente, são correlacionados positivamente com o custo total da empresa, o que é lógico e já era esperado, dado que esses parâmetros medem as variações nos custos, sendo assim caso eles se elevem o valor do custo total também se elevará. Já o parâmetro $\varphi$, que mede a economia de densidade, é correlacionado negativamente com os custos totais, dado que quanto maior a economia de densidade menor serão os custos, e quanto menor a economia de densidade maior serão os custos, a análise de correlação dos parâmetros permite fazer essas inserções, porém essa questão será apresentada mais a frente de forma mais aprofundada.

\subsubsection{Obtenção dos interceptos do modelo}

Para a obtenção dos interceptos $\alpha_{1}$ e $\alpha_{2}$, foram calculadas as médias de todas as variáveis, e depois multiplicou-se o valor da média de cada variável por cada variável, isso foi feito tendo em vista que o termo de intercepto é valor que a variável dependente assume quando todas as variáveis independentes são iguais a zero, sendo assim para calcular o valor de $\alpha_{1}$ e $\alpha_{2}$, não seria possível apenas retirar os termos constantes da regressão de demanda, sendo assim foi necessário aplicar três passos fundamentais:

$\left(1^{\circ}\right)$ Extrair a média de todas as variáveis independentes da demanda das empresas 1 e 2.

$\left(2^{\circ}\right)$ Multiplicar cada variável independente de demanda pela média obtida na operação anterior, para a empresa 1 e para a empresa 2.

$\left(3^{\circ}\right)$ Somar todas as variáveis independentes de demanda multiplicadas por suas médias, para a empresa 1 e para a empresa 2, separadamente.

A partir desses passos são obtidos os parâmetros $\alpha_{1}$ e $\alpha_{2}$, apresentados na Tabela 1 abaixo:

Tabela 1 - Exemplo de tabela

\begin{tabular}{ccccc}
\multicolumn{5}{c}{ Tabela 1 } \\
\hline qj & Coef. & Std. Err. & T & P>t \\
\hline$\alpha_{1}$ & $2.248,43$ & 244,94 & 9,18 & 0,000 \\
$\alpha_{2}$ & 720,85 & 203,61 & 3,54 & 0,000 \\
\hline
\end{tabular}


O modelo de efeitos fixos pretende controlar os efeitos das variáveis omitidas que variam entre indivíduos e permanecem constantes ao longo do tempo, ao passo que os parâmetros resposta são constantes para todos os indivíduos e em todos os períodos de tempo. Neste modelo $\alpha_{1}$ e $\alpha_{2}$, representam os interceptos a serem estimados, um para cada indivíduo, como os parâmetros resposta não variam entre os indivíduos e nem ao longo do tempo, todas as diferenças de comportamento entre os indivíduos deverão ser captadas pelo intercepto.

\section{Análise de resultados}

Os "choques em custos" simulados são exógenos, isto é, valores determinados a partir de uma situação externa às variáveis do modelo. Nesse trabalho não foi modelado como eles são gerados, mas apenas é feita uma discussão qualitativa sobre o que pode causá-los, como por exemplo, um aumento exógeno no poder dos sindicatos.

Foram feitas simulações de três cenários principais de forma a verificar os impactos de uma elevação dos custos com tripulação na competição do duopólio analisado. $\mathrm{O}$ primeiro cenário analisa o aumento de custos em um período de fraca economia de densidade. O segundo cenário representa o estimado no modelo (cenário base). O terceiro cenário analisa o aumento de custos em um período com forte economia de densidade.

A Tabela 2 apresenta os resultados para os cenários propostos sob a hipótese de choques em custos com tripulação (incremento salarial). Para a simulação foram calculados incrementos de $10 \%$ nos salários das tripulações.

Tabela 1 - Resultado Cenário Estimado

\begin{tabular}{|c|c|c|cccc|}
\hline \multicolumn{2}{|c}{ Caso } & \multirow{2}{*}{ Empresa } & $\begin{array}{c}\text { Incremento } \\
\text { salarial }\end{array}$ & $\% \Delta \mathbf{p}$ & $\mathbf{\%} \Delta \mathbf{q}$ & $\mathbf{\%} \Delta \boldsymbol{\pi}$ \\
\hline Fraca economia de & maior & $10 \%$ & $0,22 \%$ & $-0,05 \%$ & $-0,09 \%$ \\
densidade & menor & $10 \%$ & $0,47 \%$ & $-0,44 \%$ & $-0,88 \%$ \\
\hline Economia de densidade & maior & $10 \%$ & $0,24 \%$ & $-0,04 \%$ & $-0,08 \%$ \\
estimada (Caso base) & menor & $10 \%$ & $0,54 \%$ & $-0,46 \%$ & $-0,93 \%$ \\
\hline Economia de densidade & maior & $10 \%$ & $0,29 \%$ & $-0,02 \%$ & $-0,04 \%$ \\
estimada (Caso base) & menor & $10 \%$ & $0,80 \%$ & $-0,53 \%$ & $-1,05 \%$ \\
\hline
\end{tabular}

A análise da Tabela 2 permite inferir que a empresa menor, quando ocorrem choques em custos, sempre é mais afetada que a empresa maior. No cenário com fraca economia de densidade, sob a hipótese de choques em custos com tripulação, a empresa menor faz um reajuste no preço aproximadamente duas vezes maior que o valor do reajuste da empresa maior. Diante disso, dado que os passageiros da empresa menor são mais elásticos a preços, a perda de passageiros dela é aproximadamente 8,8 vezes maior que a perda de passageiros da empresa maior, ou seja, caso 
ocorra um reajuste de $10 \%$ no salário das tripulações (para ambas as empresas), a empresa maior perderá $0,05 \%$ dos passageiros, enquanto a empresa menor perderá $0,44 \%$. A lucratividade é reduzido em ambas as empresas, porém a empresa menor perde aproximadamente 9 vezes mais do que a empresa maior. ou seja, quando ocorre um reajuste de $10 \%$ nos custos com tripulação, a empresa maior perde $0,05 \%$ de lucros e a empresa menor perde $0,44 \%$ de lucros.

No caso base (cenário estimado), sob a hipótese de choques em custos com tripulação, a empresa menor faz um reajuste no preço aproximadamente 2,3 vezes maior que o reajuste da empresa maior. Como os passageiros da empresa menor são mais sensíveis a preços, a perda de passageiros da menor é de aproximadamente 11,5 vezes maior que a perda da empresa maior, ou seja, caso ocorra um reajuste de $10 \%$ no salário das tripulações (para ambas as empresas), a empresa maior perderá $0,04 \%$ de passageiros, enquanto a empresa menor perderá $0,46 \%$. Ambas as empresas sofrem perdas nos lucros, porém a empresa menor perde aproximadamente 11,7 vezes mais do que a empresa maior, ou seja, por exemplo, quando ocorre um reajuste de $10 \%$ nos custos com tripulação, a empresa maior perde $0,08 \%$ de lucros e a empresa menor perde $0,93 \%$ de lucros.

Em um cenário com forte economia de densidade, sob a hipótese de choques em custos com tripulação, a empresa menor faz um reajuste no preço aproximadamente 2,8 vezes maior que o valor do reajuste da empresa maior. Diante disso, dado que os passageiros da empresa menor são mais sensíveis a preços, a perda de passageiros nessa empresa é de aproximadamente 26,5 vezes maior que a perda da empresa maior, ou seja, caso ocorra um reajuste de $10 \%$ no salário das tripulações (para ambas as empresas), a empresa maior perderá 0,02\% de passageiros, enquanto a empresa menor perderá $0,53 \%$. A lucratividade da empresa menor caiu 26,3 vezes mais que a empresa maior. O que pode ser explicado pelas variações do custo total, pois embora, o aumento no custo total da empresa menor tenha sido menor que o aumento no custo total da empresa maior, a receita da empresa menor é muito menor que a da empresa maior. Diante disso, o tamanho beneficia a grande sob uma situação de maior economia de densidade.

A análise da Tabela 2 permite concluir que à medida que a economia de densidade é elevada, maiores são as perdas para a empresa menor. Essa situação é ilustrada na Figura 5, onde é apresentada a relação entre a lucratividade da empresa maior com a lucratividade da empresa menor, em relação à economia de densidade. 
Figura 3 - Índice de Economia de Densidade

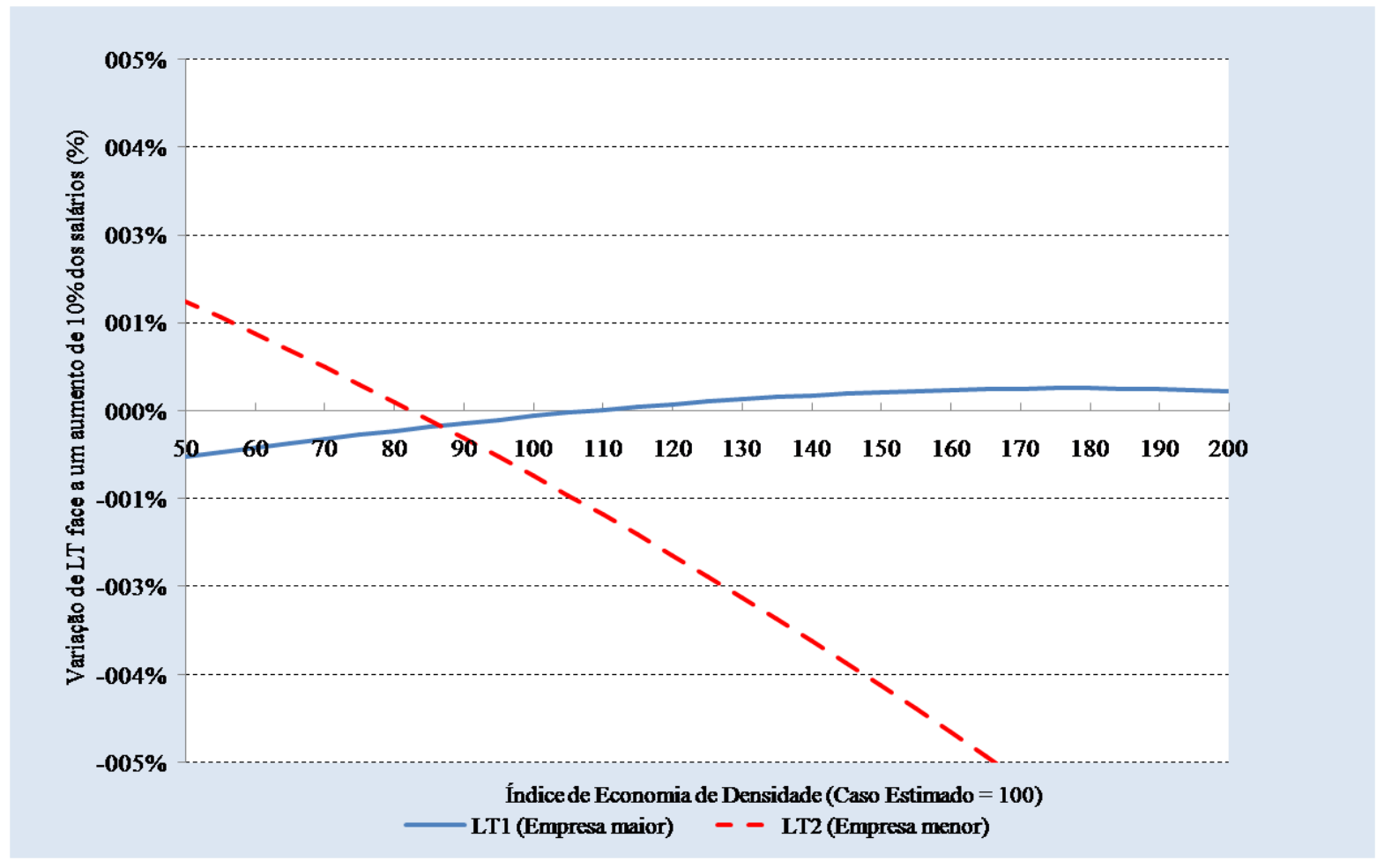

A Tabela 3 mostra uma análise dos mesmos cenários já apresentados, porém com maior elasticidade, $50 \%$, tanto para a empresa grande quanto para a empresa menor. Uma análise preliminar permite inferir que com as elasticidades elevadas, a empresa menor é mais penalizada do que no cenário menos elástico. Dado que naturalmente seus usuários são mais sensíveis a preço que os usuários da empresa maior. Essa análise se faz importante pelo fato de que toda estimação está sujeita a problemas, sobretudo de estimação viesada. Existem vários fatores que causam viés nas estimações, como exemplo, a omissão de variáveis relevantes e a endogenia de certas variáveis. Nesse trabalho, os preços são, em geral, considerados endogenamente determinados junto com as quantidades. Sendo assim, os betas podem estar inflados.

Tabela 2 - Resultados Cenário Mais Elástico

\begin{tabular}{|c|c|c|c|c|c|}
\hline Caso & Empresa & $\begin{array}{l}\text { Incremento } \\
\text { salarial }\end{array}$ & $\% \Delta \mathbf{p}$ & $\% \Delta \mathbf{q}$ & $\% \Delta \pi$ \\
\hline \multirow{2}{*}{$\begin{array}{l}\text { Fraca economia de } \\
\text { densidade }\end{array}$} & maior & $10 \%$ & $0,31 \%$ & $-0,07 \%$ & $-0,13 \%$ \\
\hline & menor & $10 \%$ & $0,61 \%$ & $-0,84 \%$ & $-1,66 \%$ \\
\hline \multirow{2}{*}{$\begin{array}{l}\text { Economia de densidade } \\
\text { estimada (Caso base) }\end{array}$} & maior & $10 \%$ & $0,35 \%$ & $-0,05 \%$ & $-0,09 \%$ \\
\hline & menor & $10 \%$ & $0,75 \%$ & $-0,92 \%$ & $-1,84 \%$ \\
\hline \multirow{2}{*}{$\begin{array}{l}\text { Economia de densidade } \\
\text { estimada (Caso base) }\end{array}$} & maior & $10 \%$ & $0,48 \%$ & $0,03 \%$ & $0,07 \%$ \\
\hline & menor & $10 \%$ & $1,34 \%$ & $-1,27 \%$ & $-2,53 \%$ \\
\hline
\end{tabular}

A análise da Tabela 3 permite inferir que a empresa menor, em um cenário mais elástico, quando ocorrem choques em custos, sempre é mais afetada que a empresa maior. No cenário com fraca economia de densidade, sob a hipótese de choques em custos com tripulação, a empresa 
menor faz um reajuste no preço de aproximadamente duas vezes maior que o valor do reajuste da empresa maior. Diante disso, dado que os passageiros da empresa menor são mais sensíveis a preços, sua perda de passageiros é aproximadamente 12 vezes maior que a perda de passageiros da empresa maior, ou seja, caso ocorra um reajuste de $10 \%$ no salário das tripulações (para ambas as empresas), a empresa maior perderá $0,07 \%$ de produto, enquanto a empresa menor perderá $0,84 \%$. O lucro é reduzido em ambas as empresas, porém a empresa menor perde aproximadamente 12,8 vezes mais do que a empresa maior, ou seja, quando ocorre um reajuste de $10 \%$ nos custos com tripulação, a empresa maior perde $0,13 \%$ de lucros e a empresa menor perde 1,66\% de lucros.

No caso base (cenário estimado), sob a hipótese de choques em custos com tripulação, a empresa menor faz um reajuste no preço aproximadamente 2,2 vezes maior que o da empresa maior. Como os passageiros da empresa menor são mais sensíveis a preços, a perda de passageiros da menor é de aproximadamente 18,4 vezes maior que a perda da empresa maior, ou seja, caso ocorra um reajuste de $10 \%$ no salário das tripulações (para ambas as empresas), a empresa maior perderá $0,05 \%$ de passageiros, enquanto a empresa menor perderá $0,92 \%$ dos passageiros. O lucro é reduzido em ambas as empresas, porém a empresa menor perde aproximadamente 20,5 vezes mais do que a empresa maior, ou seja, por exemplo, quando ocorre um reajuste de $10 \%$ nos custos com tripulação, a empresa maior perde $0,09 \%$ de lucros e a empresa menor perde $1,84 \%$ de lucros.

No cenário com forte economia de densidade, sob a hipótese de choques em custos com tripulação, a empresa menor faz um reajuste no preço aproximadamente três vezes maior que o valor do reajuste da empresa maior. Diante disso, dado que os passageiros da empresa menor são mais elásticos a preços, a perda de produto dela é de aproximadamente 42,3 vezes a perda de produto da maior, ou seja, caso ocorra um reajuste de $10 \%$ no salário das tripulações (para ambas as empresas), a empresa maior perderá $0,03 \%$ dos passageiros, enquanto a empresa menor perderá $1,27 \%$. Nesse cenário, o efeito combinado de choques em custos com forte densidade, faz com que o lucro da empresa maior seja positivo, e o da empresa menor seja negativo. Ou seja, caso ocorra choques em custos de $10 \%$, enquanto a empresa maior ganha $0,07 \%$ de lucros, a empresa menor perde $2,53 \%$ de lucro. Essa perda pode ser atribuída ao fato de que em um cenário com forte economia de densidade, com um aumento nos custos de ambas as empresas, a empresa maior começa a roubar mercado da rival, ou seja, parte dos passageiros que deixam de voar com a empresa menor passa a voar com a empresa maior. Isso pode ser atribuído ao fato de que dissídios iguais para ambas as empresas, faz com que ambas aumentem os preços. A menor aumentará mais ainda os preços, sendo assim, como seus passageiros são mais sensíveis a preços, parte de seus passageiros passam a optar por voar com um serviço melhor ou até mesmo deixam de voar.

A análise da Tabela 3 permite concluir que à medida que a economia de densidade é elevada, maiores serão as perdas para a empresa menor. Quando a elasticidade é maior, as perdas da 
empresa menor são mais acentuadas. Essa situação será ilustrada na Figura 6, onde é apresentada a relação entre a lucratividade da empresa maior com a lucratividade da empresa menor, em relação à economia de densidade.

Figura 4 - Índice de Economias de Densidade

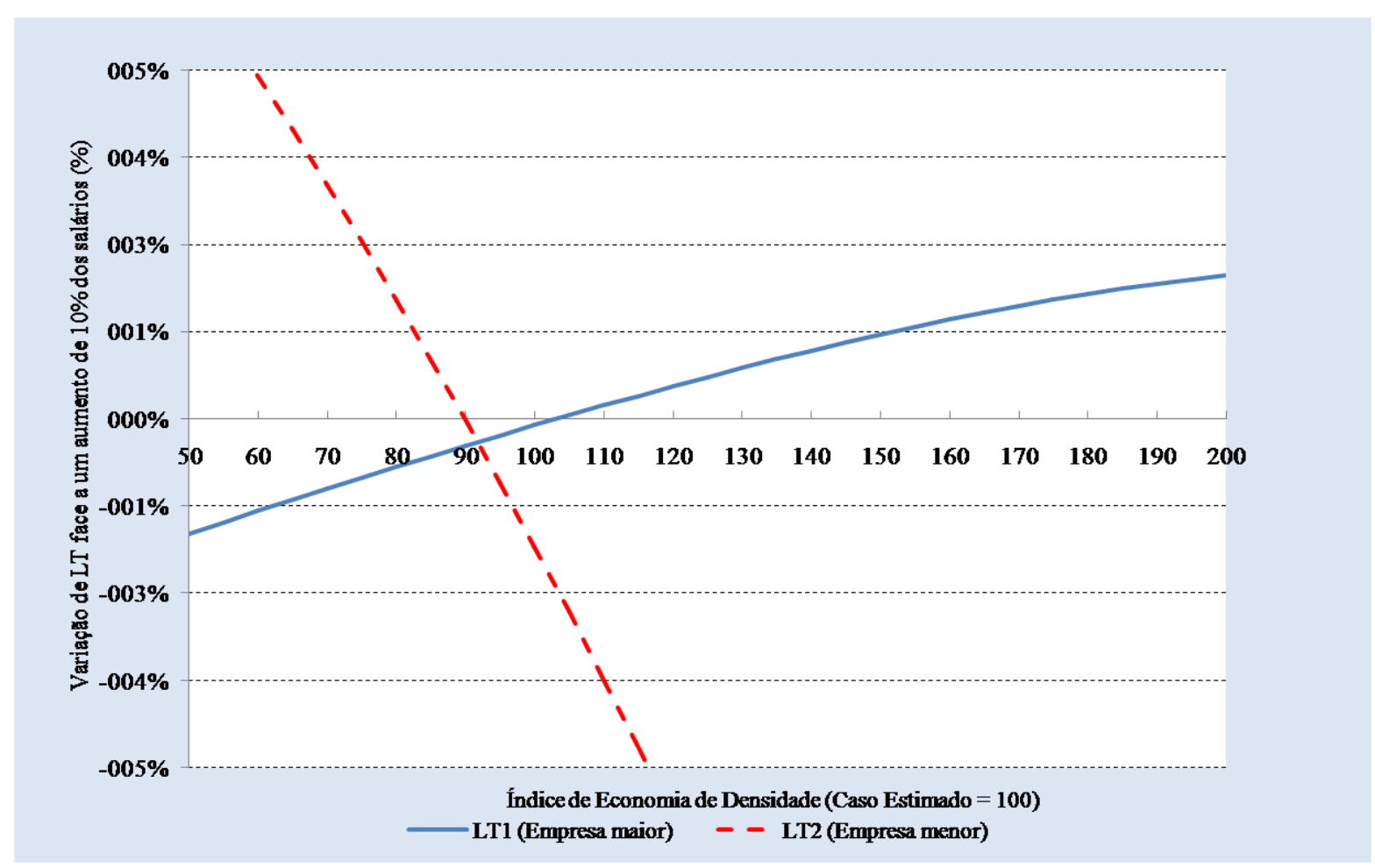

Os resultados apresentados indicam que a empresa menor é sempre mais afetada que a empresa maior. Por outro lado, quanto menor a economia de densidade menos afetada é a empresa menor, dado que ela tem menores perdas em relação a uma situação de forte economia de densidade.

Diante do fato dos resultados terem indicado que a empresa menor é sempre mais afetada que a empresa maior. Esse trabalho propõe que os dissídios salariais sejam diferenciados por tamanho de empresa, ou seja, caso ocorram choques em custos, os reajustes serão repassados de forma diferenciada de acordo com o tamanho da empresa. A empresa menor e a empresa maior receberão reajustes proporcionais aos seus tamanhos.

Para demonstrar os benefícios dessa proposição, foi simulado um cenário de choques em custos com tripulação, porém o dissídio para as empresas foi diferenciado por tamanho de empresa. A empresa menor reajustará os salários das tripulações em 5\% e a empresa maior em 10\%. Esse trabalho não fez os cálculos de quais seriam os níveis ótimos de reajuste. O intuito dessa simulação foi a de demonstrar os benefícios do dissídio diferenciado para as empresas menores. A Tabela 4 apresenta choques em custos com tripulação com dissídio diferenciado em 50\%. 
Tabela 3 - Dissídio Diferenciado Cenário Estimado

\begin{tabular}{|c|c|c|c|c|c|}
\hline Caso & Empresa & $\begin{array}{l}\text { Incremento } \\
\text { salarial }\end{array}$ & $\% \Delta p$ & $\% \Delta \mathbf{q}$ & $\% \Delta \pi$ \\
\hline $\begin{array}{l}\text { Fraca economia de } \\
\text { densidade }\end{array}$ & $\begin{array}{l}\text { maior } \\
\text { menor }\end{array}$ & $\begin{array}{l}10 \% \\
5 \% \\
\end{array}$ & $\begin{array}{l}0,18 \% \\
0,27 \%\end{array}$ & $\begin{array}{l}-0,10 \% \\
-0,13 \% \\
\end{array}$ & $\begin{array}{l}-0,19 \% \\
-0,27 \% \\
\end{array}$ \\
\hline $\begin{array}{l}\text { Economia de densidade } \\
\text { estimada (Caso base) }\end{array}$ & $\begin{array}{l}\text { maior } \\
\text { menor }\end{array}$ & $\begin{array}{l}10 \% \\
5 \% \\
\end{array}$ & $\begin{array}{l}0,20 \% \\
0,31 \% \\
\end{array}$ & $\begin{array}{l}-0,10 \% \\
-0,14 \% \\
\end{array}$ & $\begin{array}{l}-0,19 \% \\
-0,27 \% \\
\end{array}$ \\
\hline $\begin{array}{l}\text { Economia de densidade } \\
\text { estimada (Caso base) }\end{array}$ & $\begin{array}{l}\text { maior } \\
\text { menor }\end{array}$ & $\begin{array}{l}10 \% \\
5 \%\end{array}$ & $\begin{array}{l}0,24 \% \\
0,42 \%\end{array}$ & $\begin{array}{l}-0,09 \% \\
-0,14 \% \\
\end{array}$ & $\begin{array}{l}-0,19 \% \\
-0,28 \% \\
\end{array}$ \\
\hline
\end{tabular}

A análise da Tabela 4 permite inferir que caso ocorram dissídios diferenciados, as perdas da empresa menor são expressivamente atenuadas. No cenário de fraca economia de densidade, com dissídio diferenciado o reajuste de preço da menor é 1,5 vezes maior que o reajuste da rival, já o aumento de preços faz com que a empresa menor perca 1,3 mais passageiros que a empresa maior. A redução na perda de lucro foi substancial para a empresa menor, ou seja, com dissídio diferenciado a empresa menor perde 1,4 vezes mais lucro que a rival.

No cenário estimado (caso base), com dissídio diferenciado o reajuste de preços da empresa menor seria de 1,5 vezes maior que o reajuste da rival. As perdas de passageiros com dissídio diferenciado seriam aproximadamente 1,4 vezes maior que o aumento da empresa maior, por fim a perda de lucros nesse cenário, com dissídio diferenciado, seria aproximadamente 1,4 vezes maior que a perda da empresa maior.

No cenário com economia de densidade forte, caso os dissídios salariais sejam aplicados de acordo com o tamanho da empresa, a empresa menor conseguirá competir de forma menos desigual, ou seja, ela conseguirá competir com a empresa maior de forma mais homogênea. Com o reajuste nos salários das tripulações, o preço da empresa menor (com dissídio diferenciado), aumentou aproximadamente 1,7 vezes a mais que o preço da rival. Diante desse aumento dos preços, com dissídio diferente, a menor perde menos passageiros, ou seja, ela perda 1,5 vezes mais produto que a empresa maior, e consequentemente o lucro da empresa menor, com dissídio diferenciado pelo tamanho da empresa, cai 1,5 vezes mais que o lucro da rival.

Eakin e Schoech (2010) demonstram que fortes economias de densidade diminuem com o passar do tempo, dado o crescimento gradual da densidade. Essa análise confirma o que é indicado nesse trabalho, de que fortes economias de densidade representam rotas incipientes e com bom potencial de crescimento. Hendricks et al (1995) indicam que as economias de densidade com o passar do tempo explicam o surgimento de redes hub-and-spoke nos Estados Unidos no período pós-desregulamentação. Nos dias atuais essas redes são em geral bastante densas. Keeler (1983) fez um estudo para o transporte ferroviário de forma a mostrar que economias de densidade esgotadas (economia de densidade fraca) existem em rotas com potencial de crescimento. No caso do 
transporte aéreo poderiam ser rotas de menor densidade ou rotas servidas (em maior parte) por empresas menores.

O mercado aéreo brasileiro se encontra em um período de crescimento, onde nesse ponto não são demandados muitos investimentos para se operar na rota, os ganhos são altos, a probabilidade de dar certo a escolha é média, e ainda há potencial de exploração. Nesse ponto, existe economia de densidade no mercado. Além disso, essa fase de crescimento da curva é característica de países emergentes, como Brasil e China. Para a economia de densidade ser fraca, os mercados deveriam estar na fase inicial ou na fase de maturação, o que não condiz com a atual situação do Brasil.

\section{Conclusões}

Esse trabalho teve como objetivo verificar através de uma modelagem, utilizando a Teoria da Organização Industrial, os efeitos de choques exógenos nos custos com tripulação, nos preços, na demanda, no market share, na receita total e nos lucros das empresas aéreas, bem como na competitividade de empresas com tamanhos distintos. Toda essa análise foi feita para uma situação de duopólio entre uma empresa grande e uma empresa pequena, sob a hipótese de economia de densidade. Os resultados que foram obtidos nesse trabalho são intuitivos, porém uma análise como essa possibilitou a materialização dessa intuição, de forma a tornar a análise mais concreta e conseqüentemente possibilitando uma análise mais palpável.

A metodologia de análise utilizada partiu de uma análise da literatura, onde foram identificados aspectos que deveriam ser considerados em uma modelagem de competição entre empresas aéreas com produtos diferenciados, que no caso específico desse trabalho foi a economia de densidade. Dessa forma, a economia de densidade foi incorporada à modelagem algébrica, possibilitando gerar análises quantitativas quanto às vantagens que ela pode permitir que empresas de menor porte obtenham. Foram feitos quatro cenários principais, o primeiro analisando uma situação de choques em custos em um período de menor eficiência econômica, o segundo analisando uma situação de choques em custos ocorrendo em um período de maior eficiência, o terceiro analisando uma situação de choques em custos ocorrendo em um período de maior economia de densidade, e por fim o quarto cenário analisando uma situação de choques em custos ocorrendo em um período de menor economia de densidade.

A análise dos resultados desse trabalho indica que em uma situação de maior economia de densidade, as empresas menores conseguem obter vantagem em relação a outros cenários com menor economia de densidade. Dessa forma, pode-se dizer que os ganhos com densidade beneficiam significativamente as empresas menores e as tornam mais competitivas, possibilitando que elas enfrentem a competição de forma mais equilibrada com as empresas maiores. Por outro 
lado, uma situação de menor economia de densidade, ou de ausência de economia de densidade, a empresa menor sofreria muito mais com uma elevação dos custos, de forma que ela competiria com uma empresa maior com um grau muito alto de desvantagem.

Com base em toda a análise feita nesse trabalho, deve-se atentar ao fato de que a exploração da economia de densidade apresenta-se como importante estratégia de competição para empresas aéreas menores frente às empresas maiores, dessa forma as empresas menores devem encontrar formas de obterem sempre os maiores ganhos possíveis com densidade na rota. Seja através da utilização de aeronaves com tamanhos diferentes, seja através de outras formas que incentivem a economia de densidade. Vale ressaltar que a economia de densidade no âmbito da empresa pode gerar ganhos substanciais para as empresas menores, tornando-se inclusive uma importante ferramenta de gestão que possibilite à empresa tornar-se mais competitiva no mercado.

\begin{abstract}
This paper examines the impacts of shocks in crew costs on the competition between airlines with differentiated product and size asymmetries. Through numerical simulations using econometrically estimated parameters we analyzed scenarios with different assumptions regarding economies of density. The results indicate that, in a situation of exogenous increase in wages, a small airline is always more impacted than a major airline. This situation is softened by the situation of lower economies of density. The final conclusions suggest that airline competition is weakened by the fact that smaller airlines have lower bargaining power with respect to unions.
\end{abstract}

Keywords: air transport; competition; crew costs; density economies.

\title{
Referências
}

BRASIL. Anuários do Transporte Aéreo. Volume 1 - Dados Estatísticos e Volume 2 - Dados Econômicos. Agência Nacional de Aviação Civil (ANAC). Anos diversos

BENMELECH, E.; BERGMAN, N. K.; ENRIQUEZ, R. Negotiating with Labor under Financial Distress. NBER Working Paper Series, N. 17192, 2011.

BRUECKNER, J. K.; PICARD, P. M. Airline Alliances, Carve-outs and Collusion, CESIFO Working Paper, n. 3593 , 2011.

CHRISTENSEN, R. Plane Answers to Complex Questions: The Theory of Linear Models (Third ed.). New York: Springer. ISBN 0-387-95361-2, 2002. crossref

DIXIT, A. K. A Model of Duopoly Suggesting a Theory of Entry Barriers. Bell Journal of Economics, v. 10, p. 20-32, 1979. cross ref

DOGANIS, R. The Airline Business in the 21st Century. London: Routledge, 256p, 2001.

EAKIN, B. K.; SCHOECH, P. E. The distribution of the Post-Staggers act Railroad productivity gains. Christensen Associates, University Bay Drive, Madison, 2010.

FERNANDES, S. Após reunião sem acordo, greve dos aeroviários é mantida. Folha de São Paulo, 2010. Disponível em: <http://www1.folha.uol.com.br/cotidiano/849208-apos-reuniao-sem-acordo-greve-dos-aeroviarios-e-

mantida.shtml.>. Acesso em: 15 jan. 2011. 
FONSECA, C. Nota Sindicato Nacional dos Aeronautas. Sindicato Nacional dos Aeronautas. Disponível em: <http://www.sna.org.br/noticia.php?id_not=184.>. Acesso em: 10 fev. 2011.

FU, X., LIJESEN, M., OUM, T. H. An Analysis of Airport Pricing and Regulation in the Presence of Competition Between Full Service Airlines and Low Cost Carriers. Journal of Transport Economics and Policy, v. 40, n. 3, p. 425-447, 2006.

HENDRICKS, K.; PICCIONE, M.; TAN, G. The Economics of Hubs: The Case of Monopoly. Review of Economic Studies, v. 62, n. 1, p. 83-99, 1995. crossref

HIRSCH, B. T. Wage Determination in the U. S. Airline Industry: Union Power under Product Market Constraints, in D. Lee (Ed), Advances in Airline Economics, Volume 2: The Economics of Airline Institutions, Operations and Marketing. Elsevier, pp. 27-59, 2007.

KEELER, T. E. Railroads, freight, and public policy. Washington, The Brookings Institution, 1983. 180p.

SINGH, N. e VIVES, X. (1984) Price and Quantity Competition in a differentiated Duopoly. RAND Journal of Economics, v. 15, n. 4, 1983. crossref

VASSALLO, M. D. Simulação de Fusão com Variações de Qualidade no Produto das Firmas: Aplicação para o Caso do Code-Share Varig-TAM. Journal of Transport Literature, v. 4, n. 2, p. 50-100, 2010.

\section{Dados dos autores:}

Nome completo: Cícero Rodrigues de Melo Filho

Filiação institucional: Núcleo de Economia dos Transportes, Antitruste e Regulação (NECTAR/ITA). Instituto Tecnológico de Aeronáutica.

Função ou cargo ocupado: Pesquisador.

Endereço: SQS 310, Bloco D, Apartamento 311, Asa Sul, Brasília (DF). Telefone: 61-8213-4380. e-mail: ciceromelofilho@gmail.com

\section{Nome Completo: Alessandro Vinícius Marques de Oliveira}

Filiação Institucional: Núcleo de Economia dos Transportes, Antitruste e Regulação (NECTAR/ITA). Instituto Tecnológico de Aeronáutica.

Função ou cargo ocupado: Professor. Instituto Tecnológico de Aeronáutica - ITA. Divisão de Engenharia Civil - IEI.

Endereço: Praça Marechal Eduardo Gomes, 50. Cep:12.228-900 São José dos Campos - SP. e-mail: alessandro.oliveira@pq.cnpq.br / a.v.m.oliveira@gmail.com

\section{Submetido em: 11/02/2014}

Aceito em: 18/12/2014 